\title{
Dietary $\alpha$-linolenic acid from flaxseed oil improved folliculogenesis and IVF performance in dairy cows, similar to eicosapentaenoic and docosahexaenoic acids from fish oil
}

\author{
U Moallem ${ }^{1}$, A Shafran ${ }^{1,2}$, M Zachut $^{1}$, I Dekel ${ }^{1}$, Y Portnick ${ }^{1}$ and A Arieli ${ }^{2}$ \\ ${ }^{1}$ Department of Ruminant Science, Institute of Animal Sciences, the Volcani Center, PO Box 6, Bet-Dagan 50250, \\ Israel and ${ }^{2}$ Department of Animal Science, the Robert H. Smith Faculty of Agriculture, Food and Environmental \\ Quality Sciences, the Hebrew University of Jerusalem, Rehovot 76100, Israel
}

Correspondence should be addressed to U Moallem; Email: uzim@volcani.agri.gov.il

\begin{abstract}
The objectives of this study were to determine the differential incorporation of various omega-3 (n-3) fatty acids (FAs) supplemented to dairy cows into ovarian compartments and assess the effects on IVF. Forty-two 256-day pregnant cows were supplemented with encapsulated fats, in treatments designated as i) SFA - saturated fat at 240 and $560 \mathrm{~g} /$ day per cow, prepartum and post partum (PP) respectively; ii) FLX - flaxseed oil at 300 and 700 g/day per cow prepartum and PP respectively; and iii) FO - fish oil at 300 and 700 g/day per cow prepartum and PP respectively. Commencing at 60 days in lactation, ovum pickup (OPU) was performed twice weekly (20 sessions; five cows per group) and in vitro maturation and IVF were conducted. The proportion of $\alpha$-linolenic acid (ALA) was greater in follicular fluid (FF), granulosa cells, and cumulus-oocyte complexes (COCs) of FLX cows than in other groups $(P<0.001)$. The proportion of docosahexaenoic acid (DHA) was 6.7 times as great in $\mathrm{FF}$ of $\mathrm{FO}$ as in other groups $(\boldsymbol{P}<\mathbf{0 . 0 0 1})$; docosapentaenoic acid $\mathrm{n}-3$ and DHA were detected in COCs of FO but not in others. The follicle number during OPU was higher in FLX and FO than in SFA $(P<0.05)$, and the oocyte cleavage rate was higher in FLX and FO than in SFA $(P<0.01)$. Also, the percentage of oocytes that developed to blastocysts tended to be higher in both $\mathrm{n}-3$ groups than in SFA $(P<0.1)$. In conclusion, both dietary $\mathrm{n}-3$ FAs similarly improved folliculogenesis and IVF performance; therefore, ALA-rich botanical n-3 seems to be a satisfactory approach to improve oocyte quality. Reproduction (2013) 146 603-614
\end{abstract}

\section{Introduction}

In recent years, it has become well accepted that dietary fat may have beneficial effects on fertility of dairy cows directly rather than by improving the cows' energy balance (Staples et al. 1998, Mattos et al. 2000). Dietary fatty acids (FAs) may influence the functionality of reproductive tissues by changing cell membrane composition and, consequently, membrane fluidity. Membrane fluidity can affect the transfer of nutrients and other biological factors into the cell and thereby influence physiological functions of the tissue, as shown by Zeron et al. (2002). FAs may also be involved in reproductive processes as precursors of steroid hormones (via cholesterol) and of prostaglandins (via arachidonic acid (AA)). Among FA families, the polyunsaturated FAs (PUFAs) were demonstrated to be mediators in various reproductive processes, and in the last decade, major research was focused on the effects of omega- $6(n-6)$ and especially omega-3 (n-3) FAs.

Several studies have investigated the effects of specific PUFAs on follicular development and preovulatory follicle characteristics, and they yielded inconsistent results: Robinson et al. (2002) observed an increased number of medium-sized follicles in cows fed diets rich in C18:2n-6 or C18:3n-3, whereas Ponter et al. (2006) reported fewer small follicles in cows supplemented with flaxseed (rich in C18:3n-3) than in cows fed soybean (rich in C18:2n-6). In other studies, cows (Heravi Moussavi et al. 2007) and ewes (Zeron et al. 2002) supplemented with fish oil (FO) demonstrated an increased number of small follicles than control animals. However, Petit et al. (2004) found no effect on follicle growth in cows fed flaxseed, which was in agreement with the findings of Wonnacott et al. (2010) in ewes fed n-3 or n-6 PUFAs.

The effects of long-chain FAs on oocyte quality and on fertilization were also examined in several previous studies. Leroy et al. (2005) demonstrated adverse effects of saturated FAs - palmitic (C16:0) and stearic (C18:0) acids, on cleavage and development rates of blastocysts in vitro. In a study in which cows were fed with a variety of mono- and PUFAs during the summer, Bilby et al. (2006) observed no influence on quality of oocytes collected by ovum pickup (OPU), but Cerri et al. (2009) 
found a tendency for increased fertilization of oocytes and improved embryo quality in cows fed C18:2n-6 and C18:1-trans. In a study by Fouladi-Nashta et al. $(2009 b)$, inert fat containing predominantly palmitic (C:16) and oleic (C:18:1n-9) acids increased the proportion of cleaved embryos compared with soya or flaxseed oil (FLX).

In a recent study conducted in our laboratory, dietary microencapsulated FLX (rich in $\alpha$-linolenic acid (ALA)) increased the numbers of small follicles and follicles collected by OPU, and also enhanced the cleavage rate of IVF oocytes compared with the control group (Zachut et al. 2010). Animals cannot synthesize n-3 FAs de novo; therefore, these FAs need to be supplied in the diet (Wathes et al. 2007); short-chain n-3 FAs can be elongated and desaturated to form long-chain n-3 FAs (Mattos et al. 2000). In humans, FO forms the basis of the most popular nutritional supplements; it provides the long-chain n-3 FAs - eicosapentaenoic acid (EPA) and docosahexaenoic acid (DHA) - which are considered more effective than ALA (Simopoulos 2002). However, in ruminants, $\mathrm{FO}$ has been found to suppress feed intake in many studies (Donovan et al. 2000, AbuGhazaleh et al. 2002, Whitlock et al. 2002); therefore, botanical n-3 sources, such as ALA from flaxseed, might be preferable to animal sources in ruminant nutrition. Therefore, the objectives of this study were to determine the differential incorporation of two dietary n-3 sources - FLX rich in ALA and FO rich in EPA and DHA - into plasma, milk, and ovarian compartments and to assess the effects on folliculogenesis, oocyte quality, and IVF performance.

\section{Materials and methods}

\section{Cows and diets}

The procedures used were approved by the Volcani Center Animal Care Committee. The study was conducted at the Volcani Center experimental farm in Bet Dagan, Israel, and was scheduled from September through May to avoid impacts of heat stress. Forty-two multiparous, 256-day pregnant, IsraeliHolstein dry cows were stratified randomly within stratum, and strata were defined according to the following parameters: previous lactation milk and fat yields, parity, and body weight. The dietary treatments continued until 100 days in lactation and were as follows: i) SFA $(n=14)$ - fed a basal diet and supplemented with encapsulated saturated fat at 240 and $560 \mathrm{~g} /$ day per cow prepartum and post partum (PP) respectively; ii) FLX $(n=14)$ - fed a basal diet and supplemented prepartum at $300 \mathrm{~g} /$ day per cow with fat providing ALA (C18:3n-3) at $56.1 \mathrm{~g} /$ day and $\mathrm{PP}$ at $700 \mathrm{~g} /$ day per cow providing $131.0 \mathrm{~g} /$ day ALA from FLX; and iii) FO - fed a basal diet and supplemented prepartum at $300 \mathrm{~g} /$ day per cow with fat providing EPA (C20:5n-3) at 5.8 g/day and DHA (C22:6n-3) at $4.3 \mathrm{~g}$ /day and PP at $700 \mathrm{~g}$ /day per cow, providing EPA at $13.5 \mathrm{~g} /$ day and DHA at $10.0 \mathrm{~g} /$ day from FO. The fat content of the SFA supplement was $99 \%$ compared to $80 \%$ in the FLX and FO; therefore, the supplemented amounts were different among groups to maintain similar content of fat in all diets. The fat supplements were specially prepared and supplied by SILA (Venice, Italy). The ingredients and chemical composition of the dry cow rations of all treatment groups are presented in Table 1 and of the milking cow is presented in Table 2. The FA compositions of the fat supplements are presented in Table 3 and those of the whole diet in Table 4. The cows were milked three times daily and individually fed total mixed ration daily at $1100 \mathrm{~h}$.

\section{Aspiration of large follicles}

Seven cows from each group were subjected to synchronization of estrous cycles followed by aspiration of large follicles. These cows were i.m. administered with GNRH analog $(200 \mu \mathrm{g}$ gonadorelin; Gonabreed, Parnell Australia PTY, Alexandria, Australia), and 7 days later, their ovaries were monitored by ultrasound for the presence of corpus luteum (CL). Cows with $\mathrm{CL}$ on the ovaries were treated with $\mathrm{PGF}_{2 \alpha}$ analog $(500 \mu \mathrm{g}$ cloprostenol; Estroplan, Parnell Australia PTY) and estrus was visually monitored. Fourteen to 15 days after behavioral estrus, the cows received another $\mathrm{PGF}_{2 \alpha}$ injection, and $48 \mathrm{~h}$ later, the follicular fluid (FF) from follicles $>7 \mathrm{~mm}$ in diameter was aspirated according to Moallem et al. (2007). Follicles were aspirated individually with the aid of an ultrasound scanner

Table 1 Ingredients and chemical composition of the experimental dry cow's diets.

\begin{tabular}{lccc}
\hline & \multicolumn{3}{c}{ Treatments } \\
\cline { 2 - 4 } & SFA & FLX & FO \\
\hline Ingredients (\% of DM) & & & \\
Corn grain (ground) & 5.5 & 5.4 & 5.4 \\
Barley grain (rolled) & 5.5 & 5.5 & 5.5 \\
Wheat grain (rolled) & 0.7 & 0.7 & 0.7 \\
Soybean meal & 3.2 & 3.2 & 3.2 \\
Sunflower meal & 3.4 & 3.4 & 3.4 \\
Rapeseed meal & 1.3 & 1.2 & 1.2 \\
Cottonseed & 0.9 & 0.9 & 0.9 \\
Wheat bran & 5.5 & 5.5 & 5.5 \\
Wheat silage & 8.6 & 8.6 & 8.6 \\
Corn silage & 8.3 & 8.3 & 8.3 \\
Clover hay & 1.2 & 1.2 & 1.2 \\
Oats hay & 51.4 & 51.1 & 51.1 \\
Soybean molasses & 1.0 & 1.0 & 1.0 \\
Urea & 0.2 & 0.2 & 0.2 \\
Limestone & 0.3 & 0.3 & 0.3 \\
Calcium bicarbonate & 0.4 & 0.4 & 0.4 \\
Salt & 0.7 & 0.7 & 0.7 \\
Encapsulated saturated FA & 1.9 & - & - \\
Encapsulated flaxseed oil & - & 2.4 & - \\
Encapsulated fish oil & - & - & 2.5 \\
Vitamins and minerals ${ }^{\mathrm{a}}$ & 0.03 & 0.03 & 0.03 \\
Chemical composition & & & \\
NEE ${ }_{\mathrm{L}}^{\mathrm{b}}$ (My/kg DM) & 6.15 & 6.15 & 6.15 \\
Crude protein & 13.3 & 13.3 & 13.3 \\
NDF & 51.0 & 51.0 & 51.0 \\
Forage NDF & 42.9 & 42.6 & 42.6 \\
Ether extract & 3.0 & 3.1 & 3.2 \\
Ca & 0.3 & 0.3 & 0.3 \\
P & 0.1 & 0.1 & 0.1 \\
\hline a Contained 20 000 000 & & & \\
\hline
\end{tabular}

${ }^{\mathrm{a}}$ Contained $20000000 \mathrm{IU}$ vitamin A/kg, $2000000 \mathrm{IU}$ vitamin D/kg, $15000 \mathrm{IU} / \mathrm{kg}$ vitamin E, $6000 \mathrm{mg} / \mathrm{kg} \mathrm{Mn}, 6000 \mathrm{mg} / \mathrm{kg} \mathrm{Zn,} 2000 \mathrm{mg} / \mathrm{kg}$ $\mathrm{Fe}, 1500 \mathrm{mg} / \mathrm{kg} \mathrm{Cu}, 120 \mathrm{mg} / \mathrm{kg} \mathrm{l}, 50 \mathrm{mg} / \mathrm{kg} \mathrm{Se}$, and $20 \mathrm{mg} / \mathrm{kg}$ Co.

${ }^{\mathrm{b}}$ Calculated using the NRC (2001) values. 
Table 2 Ingredients and chemical composition of the experimental milking cow's diets.

\begin{tabular}{|c|c|c|c|}
\hline & \multicolumn{3}{|c|}{ Treatments } \\
\hline & SFA & FLX & $\mathrm{FO}$ \\
\hline \multicolumn{4}{|l|}{ Ingredients (\% of DM) } \\
\hline Corn grain (ground) & 10.6 & 10.5 & 10.5 \\
\hline Barley grain (rolled) & 10.7 & 10.6 & 10.6 \\
\hline Wheat grain (rolled) & 1.3 & 1.3 & 1.3 \\
\hline Soybean meal & 6.1 & 6.0 & 6.0 \\
\hline Sunflower meal & 6.6 & 6.6 & 6.6 \\
\hline Rapeseed meal & 2.4 & 2.4 & 2.4 \\
\hline Cottonseed & 1.7 & 1.7 & 1.7 \\
\hline Wheat bran & 10.7 & 10.6 & 10.6 \\
\hline Wheat silage & 16.6 & 16.5 & 16.5 \\
\hline Corn silage & 16.0 & 15.9 & 15.9 \\
\hline Clover hay & 2.2 & 2.2 & 2.2 \\
\hline Oats hay & 7.9 & 7.9 & 7.9 \\
\hline Soybean molasses & 2.0 & 1.9 & 1.9 \\
\hline Urea & 0.4 & 0.4 & 0.4 \\
\hline Limestone & 0.6 & 0.6 & 0.6 \\
\hline Calcium bicarbonate & 0.7 & 0.7 & 0.7 \\
\hline Salt & 1.3 & 1.3 & 1.3 \\
\hline Encapsulated saturated FA & 2.2 & - & - \\
\hline Encapsulated flaxseed oil & - & 2.9 & - \\
\hline Encapsulated fish oil & - & - & 2.9 \\
\hline Vitamins and minerals ${ }^{\mathrm{a}}$ & 0.1 & 0.1 & 0.1 \\
\hline \multicolumn{4}{|l|}{ Chemical composition } \\
\hline $\mathrm{NE}_{\mathrm{L}}^{\mathrm{b}}(\mathrm{MJ} / \mathrm{kg} \mathrm{DM})$ & 7.08 & 7.03 & 7.03 \\
\hline Crude protein & 16.3 & 16.2 & 16.2 \\
\hline NDF & 36.0 & 36.0 & 36.0 \\
\hline Forage NDF & 23.0 & 22.8 & 22.8 \\
\hline Ether extract & 4.7 & 4.7 & 4.8 \\
\hline $\mathrm{Ca}$ & 0.8 & 0.8 & 0.8 \\
\hline$P$ & 0.3 & 0.3 & 0.3 \\
\hline
\end{tabular}

${ }^{\mathrm{a} C}$ Contained $20000000 \mathrm{IU}$ vitamin A/kg, $2000000 \mathrm{IU}$ vitamin D/kg, $15000 \mathrm{lU} / \mathrm{kg}$ vitamin E, 6000 mg/kg Mn, 6000 mg/kg Zn, 2000 mg/kg $\mathrm{Fe}, 1500 \mathrm{mg} / \mathrm{kg} \mathrm{Cu}, 120 \mathrm{mg} / \mathrm{kg} \mathrm{I}, 50 \mathrm{mg} / \mathrm{kg} \mathrm{Se}$, and $20 \mathrm{mg} / \mathrm{kg} \mathrm{Co}$.

${ }^{\mathrm{b}}$ Calculated using the NRC (2001) values.

(Pie Medical, Maastricht, The Netherlands) connected to a 7.5 $\mathrm{MHz}$ vaginal sector transducer equipped with a needle guide and connected to a suction pump (MP86; Biometra, Goettingen, Germany) set at a flow rate of $25-30 \mathrm{ml} / \mathrm{min}$. The needles used were 18 gauge and were changed between follicles. After collection, the FF was centrifuged for $15 \mathrm{~min}$ at $3000 \mathrm{~g}$, the sediment, which contained the granulosa cells, was separated from the fluids, and both fractions were frozen at $-32{ }^{\circ} \mathrm{C}$ pending analysis.

\section{OPU procedure and oocyte collection}

Commencing at 60 days in lactation, transvaginal follicular aspiration was applied twice weekly for 10 weeks to five cows per treatment, according to Zachut et al. (2010). The cows were sedated with an i.m. injection of $1 \mathrm{ml}$ Sedaxylan (xylazine at $20 \mathrm{mg} / \mathrm{ml}$; Eurovet Animal Health, Bladel, The Netherlands) and were given a local anesthetic of $5 \mathrm{ml} \%$ lidocaine $\mathrm{HCl}$ (esracain $2 \%$, $200 \mathrm{mg} / 10 \mathrm{ml}$, Rafa Laboratories, Jerusalem, Israel) injected epidurally between the last sacral and first caudal vertebrae. Follicles were aspirated with the aid of an ultrasound scanner (Pie Medical) connected to a 7.5 MHz vaginal sector transducer equipped with a needle guide and connected to a suction pump (Craft Suction Unit pump, Rocket Medical plc,
Watford, England). For each cow in each session, follicular contents from all visible $3-7 \mathrm{~mm}$ follicles were collected into a single $50 \mathrm{ml}$ tube that contained HEPES-TL solution medium (Sigma-Aldrich Israel Ltd., Rehovot, Israel) supplemented with antibiotics and $0.008 \%$ heparin (Sigma-Aldrich Israel Ltd.) in $0.4 \%$ BSA (Sigma-Aldrich Israel Ltd.). The tubes with aspirated follicular contents were transferred to an adjacent laboratory; recovered cumulus-oocyte complexes (COCs) were counted and examined morphologically. Oocytes were classified into four categories, according to the number of layers of cumulus surrounding the oocytes and their cytoplasmic consistency, as described elsewhere (de Loos et al. 1989): grade I - spherical, symmetrical, intact oocytes of uniform size, color and texture, and entirely surrounded by three to five compact layers of cumulus cells; grade II - incomplete cumulus layer and oocyte partially denuded; grade III - cumulus expanded, oocyte denuded, and partially degenerated cumulus; and grade IV totally degenerated cumulus and oocyte.

In two sessions, oocytes of grades I and II were collected for FA profile analysis. As the individual oocyte lipid mass was well below the sensitivity of the analytical method, COCs were analyzed in groups of $\sim 30$ oocytes in two replicates per treatment.

\section{Oocyte maturation}

The procedure of oocyte maturation and fertilization was performed according to Zachut et al. (2010) with some modifications, and all solutions were prepared according to Parrish et al. (1986). Briefly, after the oocytes had been recovered and graded, all COCs were washed with oocyte wash buffer (HP-T buffer) and transferred separately for each treatment group into $2 \mathrm{ml}$ sterile conical tubes containing prewarmed maturation medium. All tubes were kept in an electrically warmed container (Minitube, Tiefenbach, Germany) at $37^{\circ} \mathrm{C}$ for about $30 \mathrm{~min}$ until arrival at the IVF laboratory. Contents of the tubes were transferred to four-well culture multidishes (Nunc, Roskilde, Denmark), with $\sim 20$ oocytes per well in $500 \mu \mathrm{l}$ TCM-199 maturation medium (Sigma-Aldrich Israel Ltd.) and incubated for $22 \mathrm{~h}$ at $38.5^{\circ} \mathrm{C}$, under humidified air containing $5 \% \mathrm{CO}_{2}$.

Table 3 Fatty acid profile of the supplements (g/100 g fatty acids).

\begin{tabular}{lccr}
\hline & \multicolumn{3}{c}{ Supplements } \\
\cline { 2 - 4 } FA $(\%)$ & SFA & FLX & FO \\
\hline C14:0 & 1.05 & 0.08 & 2.24 \\
C15:0 & 0 & 0 & 0.12 \\
C16:0 & 64.18 & 9.23 & 15.52 \\
C16:1 & - & - & 2.49 \\
C16:2 & - & - & 0.19 \\
C17:0 & - & - & 0.27 \\
C18:0 & 34.77 & 52.96 & 53.26 \\
C18:1 & - & 8.10 & 12.65 \\
C18:2n-6 & - & 6.07 & 3.15 \\
C18:3n-3 & - & 23.42 & 3.32 \\
C20:0 & - & 0.14 & 0.32 \\
C20:3 & - & - & 0.58 \\
C20:5n-3 & - & - & 2.50 \\
C22:1 & - & - & 1.52 \\
C22:6n-3 & - & - & 1.86 \\
\hline
\end{tabular}

Reproduction (2013) 146 603-614 
Table 4 Fatty acid profile of the whole experimental diets during the post partum period (g/100 g fatty acids).

\begin{tabular}{|c|c|c|c|}
\hline \multirow[b]{2}{*}{ FA $(\%)$} & \multicolumn{3}{|c|}{ Treatments } \\
\hline & CTL & FLX & $\mathrm{FO}$ \\
\hline C12:0 & 0.09 & 0.04 & 0.06 \\
\hline C14:0 & 0.81 & 0.29 & 1.22 \\
\hline C14:1 & 0 & 0 & 0.03 \\
\hline C15:0 & 0.07 & 0.08 & 0.13 \\
\hline C16:0 & 38.99 & 13.97 & 15.84 \\
\hline C16:1 & 0.20 & 0.22 & 1.36 \\
\hline C17:0 & 0.14 & 0.18 & 0.28 \\
\hline C17:1 & 0.03 & 0.10 & 0.26 \\
\hline C18:0 & 21.39 & 22.71 & 27.13 \\
\hline C18:1 & 11.04 & 15.68 & 16.55 \\
\hline C18:2n-6 & 21.45 & 25.15 & 21.76 \\
\hline C18:3n-3 & 2.11 & 14.87 & 2.67 \\
\hline C20:0 & 0.5 & 0.57 & 0.61 \\
\hline C20:1 & 0.25 & 0.36 & 1.07 \\
\hline C20:2 & 0.04 & 0.09 & 0.19 \\
\hline C20:3 & 0.08 & 0.21 & 0.17 \\
\hline C20:4 & 0.03 & 0.08 & 1.08 \\
\hline$C 20: 5 n-3$ & 0.05 & 0.09 & 1.49 \\
\hline C21:0 & 0.04 & 0.10 & 0.14 \\
\hline C22:0 & 0.28 & 0.44 & 0.41 \\
\hline C22:1 & 0.10 & 0.27 & 0.29 \\
\hline C22:2 & 0.13 & 0.16 & 0.13 \\
\hline C22:3 & 0.06 & 0.19 & 0.15 \\
\hline$C 22: 5 n-3$ & 0.02 & 0.02 & 0.64 \\
\hline$C 22: 6 n-3$ & 0.02 & 0.03 & 1.46 \\
\hline C23:0 & 0.17 & 0.03 & 0.05 \\
\hline C24:0 & 0.31 & 0.39 & 0.34 \\
\hline C24:1 & 0.05 & 0.03 & 0.15 \\
\hline
\end{tabular}

\section{IVF}

After maturation, the COCs were washed once in HEPES-TALP, mechanically denuded of cumulus cells with a pipette, and placed in their respective groups in four-well plates containing, in each well, $500 \mu \mathrm{l}$ IVF-TALP with $0.0005 \%$ heparin. Semen from a single bull was added to each well to a final concentration of $1 \times 10^{6}$ spermatozoa/ml, after which, $20 \mu$ of a solution of $0.5 \mathrm{mM}$ penicillamine (Sigma-Aldrich Israel), $0.25 \mathrm{mM}$ hypotaurine (Sigma-Aldrich Israel), and $25 \mu \mathrm{M}$ epinephrine (Sigma-Aldrich Israel) in $0.9 \%(\mathrm{w} / \mathrm{v}) \mathrm{NaCl}$ were added to each well. Sperm and oocytes were co-incubated for $18 \mathrm{~h}$ at $38.5^{\circ} \mathrm{C}$ under a humidified atmosphere of $5 \% \mathrm{CO}_{2}, 5 \% \mathrm{O}_{2}$, and $90 \% \mathrm{~N}_{2}$. Putative zygotes were washed once in IVC-TALP and were then placed into $50 \mu$ l culture drops of in vitro cleave at five to ten oocytes per drop. The oocytes were cultured at $38.5^{\circ} \mathrm{C}$ under a humidified atmosphere of $5 \% \mathrm{O}_{2}, 5 \% \mathrm{CO}_{2}$, and $90 \% \mathrm{~N}_{2}$ for another $22 \mathrm{~h}$. The proportion of oocytes that cleaved and the proportions of embryos at two-, three-, and four-cell stages were recorded $40 \mathrm{~h}$ after insemination.

\section{In vitro culture}

Following the recording of zygote cleavage at $40 \mathrm{~h}$ after insemination, i.e., day 2 after fertilization, the embryos were cultured under the same conditions as before. At day 5 after fertilization, $5 \mu$ l heat-inactivated FCS (Gibco) were added to each culture drop. At days 7-8, the embryos were checked for blastocyst formation and development stage.

\section{Hormone analysis}

Concentrations of progesterone $\left(\mathrm{P}_{4}\right)$ and estradiol $\left(\mathrm{E}_{2}\right)$ in the FF were determined with RIA (Diagnostic Products, Los Angeles, CA, USA) and that of androstenedione $\left(\mathrm{A}_{4}\right)$ in the FF was determined with RIA (Diagnostic Systems Laboratories, Webster, TX, USA). Before the determinations of $\mathrm{P}_{4}, \mathrm{E}_{2}$, and $\mathrm{A}_{4}$ concentration, the FF samples were diluted 100,500 , or 30 times respectively in order to fit the detection ranges; the minimum detectable amounts were $0.2,20$, and $0.1 \mathrm{ng} / \mathrm{ml}$ for $\mathrm{P}_{4}, \mathrm{E}_{2}$, and $\mathrm{A}_{4}$ respectively. The intra- and interassay coefficients of variation for the $\mathrm{P}_{4}, \mathrm{E}_{2}$, and $\mathrm{A}_{4}$ assays were 8.8 and $8.3 \%, 3.91$ and $3.7 \%$, and 5.9 and $4.3 \%$ respectively. Follicles were regarded as $E_{2}$-active when the $E_{2}: P_{4}$ ratio was $>1$ (Ireland \& Roche 1982), and these follicles were then subjected to further analysis.

\section{FA composition of plasma, milk fat, and ovarian compartments}

FAs in plasma, FF, granulosa cells, and COCs were extracted as described by Moallem et al. (1999). Briefly, the samples were saponified in a mixture of $60 \% \mathrm{KOH}$ and ethanol, extracted with petroleum ether, and methylated with $5 \%$ sulfuric acid in methanol. FA methyl esters were analyzed with a model $7890 \mathrm{~N}$ gas chromatograph (Agilent Technologies, Santa Clara, CA, USA) equipped with a DB-23 capillary column $(60 \mathrm{~m} \times$ $0.25 \mathrm{~mm}, 0.25 \mathrm{~mm}$; Agilent Technologies) and a flame-iodizing detector. The initial temperature of the column was set at $130{ }^{\circ} \mathrm{C}$, increased at $6.5^{\circ} \mathrm{C} / \mathrm{min}$ to $170{ }^{\circ} \mathrm{C}$, and then at $2.75^{\circ} \mathrm{C} / \mathrm{min}$ to $215^{\circ} \mathrm{C}$, at which it was held for $18 \mathrm{~min}$. Then, the temperature was increased to $230{ }^{\circ} \mathrm{C}$ at $40{ }^{\circ} \mathrm{C} / \mathrm{min}$ for the remainder of the analysis. The carrier gas was hydrogen, flowing at a linear velocity of $1.6 \mathrm{~m} / \mathrm{min}$; injection volume was $1 \mu \mathrm{l}$.

\section{Statistical analysis}

Continuous variables (milk and milk solids) were analyzed as repeated measurements using the Proc Mixed procedure, version 9.2 (SAS 2002). The milk and milk solids of the first 120 days of previous lactation were used as co-variables.

The model used was:

$Y_{i j k l}=\mu+T_{i}+L_{j}+C(T \times L)_{i j k}+\mathrm{DIM}_{i j k l}+E_{i j k l m}$

where $\mu=$ overall mean; $T_{i}=$ treatment effect, ${ }_{i}=1-3 ; L_{j}=$ parity, $j=2$ or $>2 ; C(T \times L)_{i j k}=\operatorname{cow}_{k}$ nested in treatment ${ }_{i}$ and Cow nested in parity ${ }_{j}$, DIM DIjkl $_{i a y}$ in milk as continuous variable; $E_{i j k l m}=$ random residual. The hormone concentrations in FF were analyzed with the general linear models (GLM) procedure, version 9.2 (SAS 2002).

The number of follicles, oocyte numbers and grading, and oocyte recovery rate were calculated for each cow and analyzed with the Proc Mixed procedure, version 9.2 (SAS 2002). The model included the effects of treatment, cow (nested in treatment), session, and treatment $\times$ session interaction. For matured oocytes and cleavage rate, sessions were considered as random effects and data were analyzed with the Proc Mixed procedure. The model included treatment, session, and treatment $\times$ session interaction. 
The FA profiles were analyzed with the GLM procedure (SAS 2002). Least squares means and adjusted S.E.M. are presented in the tables. The level of $P<0.05$ was accepted as statistically significant unless otherwise stated, and tendencies were reported at $0.05<P<0.10$.

\section{Results}

\section{Dry matter intake, milk yield, and milk fat $F A$} composition

During the prepartum period, no differences between dietary groups were observed in dry matter intake, but PP the intake was $6.1 \%$ higher in SFA than in FO $(25.0$ and $23.6 \mathrm{~kg} /$ day respectively; S.E.M. $=0.30, P<0.009)$. The total $\mathrm{n}-3$ FA consumed during the PP period was 26.0, 71, and $171 \mathrm{~g} /$ day for the SFA, FLX, and FO groups respectively.

No differences were observed between groups, in milk yields. The percentage of milk fat was higher in SFA than in FLX (3.80 and $3.59 \%$ respectively; S.E.M. $=0.07$, $P<0.03$ ), and the protein percentage was higher in SFA than in FO (3.14 and $3.01 \%$ respectively; S.E.M. $=0.04$, $P<0.03)$. The yields of milk fat, protein, and lactose and the amounts of fat-corrected milk (4\%) were similar between dietary groups (data not shown).

No differences among groups were observed, in concentrations of nonesterified FA in plasma, either pre- or PP, nor in prepartum glucose concentrations (data not shown); however, PP glucose concentrations in plasma were higher in FLX and FO than in SFA cows (62.3, 62.6, and $55.0 \mathrm{mg} / \mathrm{l}$ respectively; $P<0.005)$.

The FA profile of milk fat changed following FA supplementation and the proportion of ALA was three times as high in FLX as in SFA and FO cows $(0.93,0.31$, and $0.35 \%$ respectively; $P<0.001)$. The proportions of EPA and 22:5n-3 (docosapentaenoic acid n-3 (DPAn-3)) in milk fat were 3.2 times as high in $\mathrm{FO}$ as in each of the other groups, and DHA content was 14 and 20 times as high in FO as in SFA and FLX cows respectively $(P<0.001)$.

\section{Composition of FA in plasma}

As expected, the FA composition of plasma was affected by dietary treatments (Table 5 ). The proportion of ALA in plasma was 2.9 and 2.5 times as high in the FLX as in the SFA and FO groups respectively $(P<0.001)$.

Table 5 Least squares means of fatty acid profile in plasma (\% of total fatty acids).

\begin{tabular}{|c|c|c|c|c|c|}
\hline \multirow[b]{2}{*}{ FA (\%) } & \multicolumn{3}{|c|}{ Treatments $^{\mathrm{a}}$} & \multirow[b]{2}{*}{ S.E.M. } & \multirow[b]{2}{*}{$P$ value } \\
\hline & SFA & FLX & $\mathrm{FO}$ & & \\
\hline C14:0 & $1.19^{*}$ & $0.85^{\dagger}$ & $0.81^{\dagger}$ & 0.08 & 0.002 \\
\hline C16:0 & 16.98 & 15.81 & 15.46 & 0.55 & NS \\
\hline C16:1 & $0.73 *$ & $0.63^{+}$ & $0.48^{\ddagger}$ & 0.02 & 0.001 \\
\hline C16:3 & 1.37 & 1.07 & 1.13 & 0.11 & NS \\
\hline C18:0 & 0.58 & 0.72 & 0.53 & 0.09 & NS \\
\hline C18:1n-9 & 7.44 & 7.04 & 6.51 & 0.59 & NS \\
\hline C18:1n-7 & 0.78 & 0.58 & 1.56 & 0.41 & NS \\
\hline C18:2n-6 & 49.99 & 48.23 & 52.07 & 1.09 & NS \\
\hline C18:3n-6 & $1.11^{*}$ & $0.67^{\dagger}$ & $0.41^{\dagger}$ & 0.1 & 0.006 \\
\hline C18:3n-3 & $2.45^{\ddagger}$ & $7.1^{*}$ & $2.9^{\dagger}$ & 0.07 & 0.001 \\
\hline C18:4 & 0.14 & 0.18 & 0.15 & 0.04 & NS \\
\hline C20:1n-9 & 0.18 & 0.16 & 0.21 & 0.04 & NS \\
\hline C20:3 & $1.81^{*}$ & $1.21^{+}$ & $0.78^{\ddagger}$ & 0.08 & 0.001 \\
\hline C20:4n-6 & $1.68^{*}$ & $1.19^{\dagger}$ & $1.02^{+}$ & 0.09 & 0.001 \\
\hline C20:4n-3 & 0.08 & 0.10 & 0.03 & 0.06 & NS \\
\hline C20:5n-3 & $0.23^{\dagger}$ & $0.47^{+}$ & $1.43^{*}$ & 0.11 & 0.001 \\
\hline$C 22: 5 n-3$ & $0.09^{\ddagger}$ & $0.17^{\dagger}$ & $0.24 *$ & 0.04 & 0.006 \\
\hline C22:5n-6 & 0.04 & 0.03 & 0.01 & 0.01 & NS \\
\hline C22:6n-3 & $0.04^{+}$ & $0.06^{\dagger}$ & $0.43^{*}$ & 0.02 & 0.001 \\
\hline C22:6n-6 & 0.04 & 0.11 & 0.14 & 0.03 & NS \\
\hline C24:1n-9 & 0.35 & 0.51 & 0.41 & 0.09 & NS \\
\hline$n-3^{b}$ & $2.75^{\ddagger}$ & $7.78^{*}$ & $5.18^{\dagger}$ & 0.13 & 0.001 \\
\hline$n-6^{c}$ & $52.79^{*},+$ & $50.31^{+}$ & $53.71^{*}$ & 1.07 & 0.03 \\
\hline Saturated $^{d}$ & $31.20^{*}$ & $30.10^{*,+}$ & $29.33^{+}$ & 0.66 & 0.05 \\
\hline MUFA $^{\mathrm{e}}$ & 9.55 & 9.09 & 9.53 & 0.85 & NS \\
\hline PUFA $^{f}$ & $55.67^{+}$ & $57.77^{*,+}$ & $58.90^{*}$ & 1.18 & 0.05 \\
\hline$n-6 / n-3$ & $19.08^{*}$ & $7.31^{\neq}$ & $11.31^{+}$ & 0.58 & 0.001 \\
\hline
\end{tabular}


The proportion of EPA was 6.2 and 3.0 times as high in the FO as in the SFA and FLX groups respectively $(P<0.001)$. The percentage of DPAn-3 in FO cows was 2.5 and 1.5 times as high as those in SFA and FLX respectively $(P<0.006)$. The percentage of $\mathrm{C} 20: 4 \mathrm{n}-6(\mathrm{AA})$ was higher in SFA animals than in the other two groups. The proportion of DHA in FO cows was 11 and seven times as high as in SFA and FLX cows respectively $(P<0.001)$. Also, the total proportion of $\mathrm{n}-3$ FAs in plasma was highest in FLX cows, intermediate in $\mathrm{FO}$, and lowest in SFA cows $(P<0.001)$. Thus, the $\mathrm{n}-6: \mathrm{n}-3$ ratio in plasma varied, being highest in SFA and lowest in FLX cows, with intermediate values in the FO group $(P<0.001)$.

\section{Composition of FA in FFs}

The effects of dietary treatments on the composition of FF obtained from $\mathrm{E}_{2}$-active follicles are presented in Table 6 . The proportion of ALA in FLX cows was 2.6 and three times as high as in SFA and FO cows respectively $(P<0.001)$, whereas the proportion of EPA in FO cows was 2.5 times as high as that in both other groups $(P<0.03)$. The proportion of DHA in FO cows was
9.3 times as high as in the other two groups $(P<0.001)$. The total proportion of $n-3$ FAs in FLX cows was 2.2 and 1.7 times as high as in SFA and FO groups respectively $(P<0.001)$. Although the proportions of total SFA, MUFA, and PUFA were similar between groups, the n-6:n-3 ratio in FF differed among the groups and was higher in SFA than in the other two groups $(P<0.001)$.

\section{Composition of FA in granulosa cells obtained from preovulatory follicles}

The FA composition in granulosa cells obtained from preovulatory follicles was also affected by dietary treatments (Table 7): C18:2n-6 was the predominant FA in granulosa cells, and its proportion tended to be higher in SFA than in FO cows $(P<0.06)$. The percentage of ALA in FLX cows' granulosa cells was 2.5 and 2.9 times as high as in those of SFA and FO cows respectively $(P<0.01)$, and the proportion of AA in those of SFA animals was 1.6 and 2.2 times as high as those in FLX and FO cows respectively $(P<0.001)$.

The proportion of EPA in granulosa cells was about twice as high in FO cows as in the SFA and FLX groups

Table 6 Least squares means of fatty acid profile in follicular fluid obtained from preovulatory follicles (\% of total fatty acids).

\begin{tabular}{|c|c|c|c|c|c|}
\hline \multirow[b]{2}{*}{ FA (\%) } & \multicolumn{3}{|c|}{ Treatments $^{\mathrm{a}}$} & \multirow[b]{2}{*}{ S.E.M. } & \multirow[b]{2}{*}{$\boldsymbol{P}<$} \\
\hline & SFA & FLX & $\mathrm{FO}$ & & \\
\hline$n$ & 8 & 9 & 8 & & \\
\hline C14:0 & 1.32 & 1.07 & 1.85 & 0.24 & NS \\
\hline C16:0 & 18.02 & 17.98 & 22.19 & 1.47 & NS \\
\hline C16:1 & 1.03 & 1.14 & 1.19 & 1.16 & NS \\
\hline C16:2 & 0.75 & 0.83 & 0.43 & 0.16 & NS \\
\hline C16:3 & 0.86 & 0.67 & 0.69 & 0.10 & NS \\
\hline C18:0 & 12.43 & 13.52 & 14.77 & 1.18 & NS \\
\hline C18:1n-9 & 10.90 & 8.47 & 11.21 & 0.87 & NS \\
\hline C18:1n-7 & 0.48 & 0.31 & 0.21 & 0.10 & NS \\
\hline$C 18: 2 n-6$ & 45.38 & 45.48 & 40.99 & 2.38 & NS \\
\hline C18:3n-6 & $0.84 *$ & $0.46^{+}$ & $0.27^{+}$ & 0.08 & 0.01 \\
\hline C18:3n-3 & $2.20^{\dagger}$ & $5.69 *$ & $1.90^{\dagger}$ & 0.37 & 0.001 \\
\hline C18:4n-3 & 0.11 & 0.20 & 0.15 & 0.04 & NS \\
\hline C20:1n-9 & 0.98 & 0.68 & 0.72 & 0.16 & NS \\
\hline C20:3 & $1.73^{*}$ & $0.99^{+}$ & $0.69^{+}$ & 0.08 & 0.001 \\
\hline C20:4n-6 & $1.90^{*}$ & $1.30^{\dagger}$ & $1.13^{+}$ & 0.11 & 0.004 \\
\hline C20:4n-3 & 0.13 & 0.10 & 0.10 & 0.04 & NS \\
\hline$C 20: 5 n-3$ & $0.29^{\dagger}$ & $0.32^{\dagger}$ & $0.76^{*}$ & 0.12 & 0.03 \\
\hline C22:5n-3 & 0.10 & 0.13 & 0.26 & 0.04 & NS \\
\hline$C 22: 6 n-3$ & $0.03^{\dagger}$ & $0.03^{\dagger}$ & $0.28^{*}$ & 0.03 & 0.001 \\
\hline C24:1n-9 & 0.49 & 0.56 & 0.38 & 0.11 & NS \\
\hline$n-3^{b}$ & $2.78^{\dagger}$ & $6.10^{*}$ & $3.53^{\dagger}$ & 0.35 & 0.001 \\
\hline$n-6^{c}$ & 48.12 & 47.25 & 42.41 & 2.45 & NS \\
\hline Saturated $^{\mathrm{d}}$ & 31.77 & 32.58 & 38.80 & 2.75 & NS \\
\hline MUFA $^{\mathrm{e}}$ & 13.88 & 11.16 & 13.30 & 0.93 & NS \\
\hline PUFA $^{f}$ & 53.29 & 54.39 & 48.32 & 2.86 & NS \\
\hline$n-6 / n-3$ & $17.37^{*}$ & $7.64^{\neq}$ & $12.52^{+}$ & 0.75 & 0.001 \\
\hline
\end{tabular}


Table 7 Least squares means of fatty acid profile in granulosa cells obtained from preovulatory follicles (\% of total fatty acids).

\begin{tabular}{|c|c|c|c|c|c|}
\hline \multirow[b]{2}{*}{ FA $(\%)$} & \multicolumn{3}{|c|}{ Treatments $^{\mathrm{a}}$} & \multirow[b]{2}{*}{ S.E.M. } & \multirow[b]{2}{*}{$\boldsymbol{P}<$} \\
\hline & SFA & FLX & $\mathrm{FO}$ & & \\
\hline C14:0 & $0.81^{\dagger}$ & $1.51^{*,+}$ & $1.74^{*}$ & 0.31 & 0.04 \\
\hline C16:0 & $19.57^{\dagger}$ & $23.05^{*,+}$ & $25.33^{*}$ & 1.22 & 0.004 \\
\hline C16:1 & 1.56 & 2.23 & 2.17 & 0.30 & NS \\
\hline C16:2 & 1.18 & 1.76 & 1.31 & 0.22 & NS \\
\hline C16:3 & 0.79 & 0.91 & 0.75 & 0.09 & NS \\
\hline C18:0 & $14.67^{*,+}$ & $13.62^{+}$ & $16.99 *$ & 0.94 & 0.02 \\
\hline C18:1n-9 & 14.64 & 15.83 & 15.17 & 1.76 & NS \\
\hline C18:1n-7 & 1.17 & 1.73 & 1.25 & 0.03 & NS \\
\hline C18:2n-6 & 38.06 & 31.93 & 29.85 & 2.94 & NS \\
\hline C18:3n-6 & $0.62 *$ & $0.27^{+}$ & $0.11^{\ddagger}$ & 0.04 & 0.02 \\
\hline C18:3n-3 & $1.65^{\dagger}$ & $4.10^{*}$ & $1.41^{\dagger}$ & 0.19 & 0.01 \\
\hline C18:4n-3 & 0.21 & 0.38 & 0.32 & 0.07 & NS \\
\hline C20:1n-9 & 0.34 & 0.65 & 0.99 & 0.25 & NS \\
\hline C20:3 & $1.40^{*}$ & $0.68^{+}$ & $0.49^{+}$ & 0.05 & 0.03 \\
\hline C20:4n-6 & $2.54 *$ & $1.60^{\dagger}$ & $1.17^{+}$ & 0.17 & 0.001 \\
\hline C20:4n-3 & $0.34 *$ & $0.20^{+}$ & $0.15^{+}$ & 0.05 & 0.05 \\
\hline C20:5n-3 & $0.23^{+}$ & $0.19^{+}$ & $0.47^{*}$ & 0.07 & 0.02 \\
\hline$C 22: 5 n-3$ & $0.20^{\dagger}$ & $0.24^{*,+}$ & $0.40^{*}$ & 0.06 & 0.03 \\
\hline C22:6n-3 & 0.01 & 0.01 & 0 & 0.01 & NS \\
\hline$n-3^{b}$ & $2.64^{+}$ & $4.71 *$ & $2.99^{\dagger}$ & 0.24 & 0.001 \\
\hline$n-6^{c}$ & $41.22 *$ & $33.80^{*,+}$ & $31.13^{+}$ & 2.92 & 0.03 \\
\hline Saturated $^{d}$ & $35.04^{+}$ & $38.18^{+}$ & $44.07^{*}$ & 1.65 & 0.02 \\
\hline MUFA $^{\mathrm{e}}$ & 17.71 & 20.43 & 19.58 & 1.91 & NS \\
\hline PUFA $^{f}$ & $47.23 *$ & $43.48^{*,+}$ & $38.25^{+}$ & 2.88 & 0.03 \\
\hline$n-6 / n-3$ & $16.05^{*}$ & $7.55^{\dagger}$ & $10.92^{+}$ & 1.06 & 0.002 \\
\hline
\end{tabular}

${ }^{*, t, \neq}$ Within rows, means with different superscript letters are statistically different.

${ }^{a}$ Treatments - cows were supplemented with encapsulated fats: SFA - saturated fat at 300 and $560 \mathrm{~g} /$ day per cow pre- and post partum (PP) respectively; FLX - 300 and $700 \mathrm{~g} /$ day per cow prepartum and PP respectively with fat providing ALA from flaxseed oil at 56.1 and $131.0 \mathrm{~g} /$ day per cow respectively; and FO - 300 and $700 \mathrm{~g} /$ day per cow prepartum and PP respectively with fat from fish oil providing EPA and DHA at 5.8 and $4.3 \mathrm{~g} /$ day per cow respectively prepartum and 13.5 and $10.0 \mathrm{~g}$ /day per cow respectively post partum. ${ }^{\mathrm{b}}$ Total n-3 FAs. ${ }^{\mathrm{C}}$ Total n-6 FAs.

${ }^{\mathrm{d}}$ Total saturated FAs. ${ }^{\mathrm{e}}$ Total monounsaturated FAs. ${ }^{\mathrm{f}}$ Total polyunsaturated FAs.

$(P<0.02)$, and the content of DPAn-3 in FO cows' granulosa cells was twice as high as that in those of SFA cows $(P<0.03)$. The total percentage of $n-3$ FAs in granulosa cells was higher in FLX cows than in the other groups $(P<0.001)$; the total proportion of $n-6$ FA in SFA cows tended to be higher than that in FLX ones $(P<0.09)$ and was higher than that in $\mathrm{FO}$ animals $(P<0.02)$. The total $n-6: n-3$ ratio in granulosa cells was higher in SFA than in either of the other groups $(P<0.05)$.

\section{FA composition of COCs}

The FA composition of COCs is presented in Table 8. The proportion of C18:0 FA in COCs was $\sim 7 \%$ lower in FO cows than in the other groups $(P<0.01)$. The percentage of ALA in COCs of FLX cows was 3.2 and 2.4 times as high as in those of SFA and FO cows respectively $(P<0.005)$. DPAn-3 and DHA were not detected in COCs of SFA and FLX cows, whereas the percentages of these FAs in FO COCs were 1.11 and $1.17 \%$ respectively $(P<0.2)$. The total proportion of $\mathrm{n}-3 \mathrm{FAs}$ tended to be higher in COCs of FO cows than in those of the other groups $(P<0.1)$, and the $\mathrm{n}-6: \mathrm{n}-3$ ratio was numerically lower in FO cows' COCs than in those of the other dietary groups $(P<0.3)$.

\section{Concentrations of hormones in preovulatory follicles}

No differences between dietary groups were observed in concentrations or contents of $\mathrm{P}_{4}, \mathrm{~A}_{4}$, or $\mathrm{E}_{2}$ in $\mathrm{FF}$ of $E_{2}$-active follicles. Also, the diameters and volumes of the follicles, as well as $\mathrm{E}_{2}: \mathrm{P}_{4}$ ratios, were similar among all the groups (data not shown).

\section{Number of oocytes obtained by OPU, cleavage rate, and development to blastocysts}

In total, 915 oocytes were aspirated in 20 OPU sessions (Table 9). The number of observed follicles $(3-7 \mathrm{~mm}$ in diameter) that were collected from the FLX and FO cows during OPU procedures was higher than that from the SFA cows $(P<0.05$; Fig. 1$)$, and the number of oocytes recovered per cow was higher in the FLX than in the SFA group $(P<0.02)$. The number of oocytes per cow that were chosen for IVM and IVF in each session was also higher in FLX cows than in SFA ones $(P<0.04)$. As shown in Table 9, the cleavage rate of oocytes was higher in FLX and FO cows than in SFA ones $(P<0.01)$, and the number of cleaved oocytes per session was also higher in the FLX and FO groups than in the SFA group $(P<0.03)$. The percentage of 
Table 8 Least squares means of fatty acid profile in cumulus-oocyte complex (COC; \% of total fatty acids).

\begin{tabular}{|c|c|c|c|c|c|c|}
\hline \multirow[b]{2}{*}{ FA $(\%)$} & \multicolumn{4}{|c|}{ Treatments $^{\mathrm{a}}$} & \multirow[b]{2}{*}{ S.E.M. } & \multirow[b]{2}{*}{$\boldsymbol{P}<$} \\
\hline & SFA & FLX & $\mathrm{FO}$ & FLX & & \\
\hline C14:0 & 4.79 & 4.58 & 5.49 & 4.58 & 0.35 & NS \\
\hline C16:0 & 27.46 & 29.68 & 29.99 & 29.68 & 3.21 & NS \\
\hline C16:1 & $3.96^{*}$ & $2.27^{+}$ & $3.2^{*, t}$ & $2.27^{+}$ & 0.26 & 0.01 \\
\hline C16:2 & 0.99 & 1.84 & 2.03 & 1.84 & 0.56 & NS \\
\hline C16:3 & 0.88 & 1.08 & 1.29 & 1.08 & 0.20 & NS \\
\hline C18:0 & $30.38^{*}$ & $32.32 *$ & $24.39^{\dagger}$ & $32.32 *$ & 0.93 & 0.02 \\
\hline C18:1n-9 & 17.71 & 15.68 & 17.99 & 15.68 & 2.13 & NS \\
\hline C18:1n-7 & 1.11 & 1.10 & 1.57 & 1.10 & 0.28 & NS \\
\hline C18:2n-6 & 6.39 & 6.43 & 6.00 & 6.43 & 1.46 & NS \\
\hline C18:3n-3 & $0.29^{\dagger}$ & $0.93^{*}$ & $0.39^{\dagger}$ & $0.93^{*}$ & 0.06 & 0.005 \\
\hline C18:4n-3 & 0.4 & 0.5 & 0.37 & 0.5 & 0.2 & NS \\
\hline C20:1n-9 & $3.33 *$ & $0.79^{+}$ & $2.59^{*,+}$ & $0.79^{+}$ & 0.47 & 0.03 \\
\hline C20:3 & 0.42 & 0.51 & 0.21 & 0.51 & 0.17 & NS \\
\hline$C 20: 4 n-6$ & 0.34 & 1.24 & 0.66 & 1.24 & 0.45 & NS \\
\hline C20:5n-3 & 1.51 & 1.01 & 1.5 & 1.01 & 0.43 & NS \\
\hline C22:5n-3 & 0 & 0 & 1.17 & 0 & 0.55 & NS \\
\hline$C 22: 6 n-3$ & 0 & 0 & 1.11 & 0 & 0.52 & NS \\
\hline$n-3^{b}$ & 2.21 & 2.44 & 4.54 & 2.44 & 0.68 & 0.1 \\
\hline$n-6^{c}$ & 6.74 & 7.67 & 6.66 & 7.67 & 1.88 & NS \\
\hline Saturated $^{d}$ & 62.64 & 66.59 & 59.88 & 66.59 & 2.80 & NS \\
\hline MUFA $^{\mathrm{e}}$ & 26.11 & 19.84 & 25.36 & 19.84 & 2.50 & NS \\
\hline PUFA $^{f}$ & 11.25 & 13.55 & 14.74 & 13.55 & 2.36 & NS \\
\hline$n-6 / n-3$ & 3.04 & 3.14 & 1.61 & 3.14 & 0.81 & NS \\
\hline
\end{tabular}

${ }^{*,+}$ Within rows, means with different superscript letters are statistically different.

${ }^{a}$ Treatments - cows were supplemented with encapsulated fats: SFA - saturated fat at 300 and 560 g/day per cow pre- and post partum (PP) respectively; FLX - 300 and 700 g/day per cow prepartum and PP respectively with fat providing ALA from flaxseed oil at 56.1 and $131.0 \mathrm{~g}$ /day per cow respectively; and FO - 300 and $700 \mathrm{~g}$ /day per cow prepartum and PP respectively with fat from fish oil providing EPA and DHA at 5.8 and 4.3 g/day per cow respectively prepartum and 13.5 and $10.0 \mathrm{~g} /$ day per cow respectively post partum. ${ }^{\mathrm{b}}$ Total n-3 FAs. ${ }^{\mathrm{C}}$ Total n-6 FAs.

${ }^{\mathrm{d}}$ Total saturated FAs. ${ }^{\mathrm{e}}$ Total monounsaturated FAs. ${ }^{\mathrm{f}}$ Total polyunsaturated FAs.

blastocysts per fertilized oocyte tended to be higher in FLX and FO than in SFA $(P<0.1)$.

\section{Discussion}

The main finding of this study is that dietary FLX was as effective as FO in improving folliculogenesis and IVF performance in dairy cows, even though differing incorporation of n-3 FAs into plasma and ovary components was demonstrated.

\section{FA profile in plasma and ovarian compartments}

In several previous studies, a variety of flaxseed sources enhanced the proportion of ALA in blood (Petit et al. 2004, Gonthier et al. 2005, Zachut et al. 2010). The results of this study support our previous findings

Table 9 Follicle and oocyte numbers, maturation, and cleavage rates of oocytes collected by ovum pickup (OPU).

\begin{tabular}{|c|c|c|c|c|c|}
\hline & \multicolumn{3}{|c|}{ Treatments $^{\mathrm{a}}$} & \multirow[b]{2}{*}{ S.E.M. } & \multirow[b]{2}{*}{$\boldsymbol{P}<$} \\
\hline & SFA & FLX & $\mathrm{FO}$ & & \\
\hline Follicle number/cow per session & $8.0^{+}$ & $10.7^{*}$ & $9.6^{*}$ & 0.55 & 0.05 \\
\hline Total number of oocytes aspirated & 248 & 361 & 306 & & \\
\hline Oocytes recovered/cow per session & $3.3^{+}$ & $4.8^{*}$ & $3.9^{*}$ & 0.3 & 0.06 \\
\hline $\begin{array}{l}\text { No. of oocytes/cow per session } \\
\text { chosen for IVM+IVF }\end{array}$ & $2.88^{\dagger}$ & $3.84^{*}$ & $3.5^{*,+}$ & 1.6 & 0.05 \\
\hline Cleavage rate $(\%)$ & $35^{+}$ & $52 *$ & $48^{*}$ & 0.03 & 0.01 \\
\hline No. of cleaved oocytes/session & $5.1^{+}$ & $9.2^{*}$ & $8.3^{*}$ & 1.1 & 0.03 \\
\hline No. of cleaved oocytes/cow per session & $1.06^{+}$ & $1.97^{*}$ & $1.66^{*}$ & 0.21 & 0.04 \\
\hline No. of blastocysts/session & 1.80 & 2.28 & 2.14 & 0.4 & 0.4 \\
\hline Rate of blastocysts from oocytes for IVF (\%) & 8.8 & 15.2 & 13.4 & 0.02 & 0.1 \\
\hline
\end{tabular}

${ }^{*},+$ Within rows, means with different superscript letters are statistically different.

${ }^{a}$ Treatments - cows were supplemented with encapsulated fats: SFA - saturated fat at 300 and $560 \mathrm{~g} /$ day per cow pre- and post partum (PP) respectively; FLX - 300 and $700 \mathrm{~g} /$ day per cow prepartum and PP respectively with fat providing ALA from flaxseed oil at 56.1 and 131.0 g/day per cow respectively; and FO - 300 and 700 g/day per cow prepartum and PP respectively with fat from fish oil providing EPA and DHA at 5.8 and 4.3 g/day per cow respectively prepartum and 13.5 and $10.0 \mathrm{~g}$ /day per cow respectively post partum. 




Figure 1 Ovum pickup and IVF performance of cows supplemented with encapsulated fats: SFA - saturated fat at 300 and $560 \mathrm{~g}$ /day per cow preand post partum (PP) respectively; FLX - 300 and 700 g/day per cow prepartum and PP respectively with fat providing ALA from flaxseed oil at 56.1 and $131.0 \mathrm{~g} /$ day per cow respectively; and FO - 300 and $700 \mathrm{~g} /$ day per cow prepartum and PP respectively with fat from fish oil providing EPA and DHA at 5.8 and $4.3 \mathrm{~g} /$ day per cow respectively prepartum and 13.5 and $10.0 \mathrm{~g} /$ day per cow respectively post partum. Different superscript letters are statistically different. The results are from 20 OPU and 18 IVF consecutive sessions (five cows per group twice weekly).

that large amounts of dietary ALA were effectively transferred into the plasma and that the incorporation rate was proportional to the amount consumed (Zachut et al. 2011). There was also slightly more plasma ALA in the FO group than in the SFA one, most likely because of the small amount of ALA provided by the FO supplement. This small proportion of ALA in FO was also reported by Childs et al. (2008), but without increased plasma ALA in beef heifers fed FO. In this study, the proportions of the longer n-3 FAs - EPA and DPAn-3 - were higher in the FLX than in the SFA cows, which indicates elongation of ALA into longer n-3 FAs. The EPA and DPAn-3 are intermediate products in the elongation and desaturation that occur during the synthesis of DHA from ALA in mammals (Wang et al. 2005). Petit et al. (2004) found that ALA supplementation increased the proportion of EPA but not of other longer n-3 FAs. Also, the proportion of DHA was dramatically increased in plasma of the FO cows, which indicates successful transfer of this important FA from the diet into the blood.

In general, the profile of FAs in FF was very similar to that in plasma, as was also reported in other studies (Zeron et al. 2002, Zachut et al. 2011). This indicates that there is relatively free passage of plasma components into the FF, which is a crucial condition for altering ovarian activity and oocyte environment by absorption of blood factors exclusively from dietary supplementation.

Dietary FAs altered the granulosa FA profile, as was also found by Zachut et al. (2010) in cows fed microencapsulated FLX and by Wonnacott et al. (2010) in ewes fed a mix of flaxseed and FO. By contrast, Fouladi-Nashta et al. (2009b) found changes in plasma
FA composition in response to dietary PUFAs, without any effect on the FA composition in granulosa cells. The development of primordial follicles into larger pre-antral and then into ovulatory follicles takes $\sim 4-6$ months in cattle (Evans et al. 2012), and the subsequent growth from $\sim 0.3$ to $3-5 \mathrm{~mm}$ in diameter takes more than 30 days (Mossa et al. 2012). Fouladi-Nashta et al. (2009b) continued the dietary FA supplementation for only a short time of 25 days compared with the 80-100 days in this study, which may account for the difference between the responses obtained in these studies. In this study, the $\mathrm{n}-6: \mathrm{n}-3$ ratio in the granulosa cells was changed in a similar manner to that in the plasma and FF; moreover, the ratios were similar to that observed in the plasma and $\mathrm{FF}$, in contrast to the findings of Adamiak et al. (2006) and Fouladi-Nashta et al. (2009b), who reported lower n-6:n3 ratios in granulosa cells than in plasma.

The FA profile of COCs was also altered by dietary n-3 FA in a manner similar to those of FF and granulosa cells. The proportion of ALA in oocytes was relatively low, although it was greater in the FLX COCs. However, although less EPA and DHA were incorporated into plasma and FF, the integration of these FAs into COCs was distinctly greater than that of ALA so that, consequently, the total n-3 FA content was about twice as great in FO cows as in either of the other groups. This might indicate selective uptake of different n-3 FAs into COCs, in which the longer n-3 FAs entering the oocytes more readily than the shorter n-3 FAs, such as ALA. A similar pattern of selective uptake of n-3 FAs was also demonstrated in maternal-fetal transfer through the placenta of these FAs, in which DHA was readily transferred from dam to calf blood, whereas ALA was barely transferred (Moallem \& Zachut 2012).

There are several differences between FA composition in oocytes and that in FF and granulosa cells: the former contains a higher proportion of saturated FAs at the expense of PUFAs and a considerably lower $n-6: n-3$ ratio in oocytes than in all other ovarian compartments. In this study, the saturated FAs in plasma and FF formed $\sim 30 \%$ of the total FAs, and this proportion increased to $35-45 \%$ in granulosa cells and to $60-67 \%$ in COCs. Reis et al. (2002) examined the FA profiles of ovine granulosa cells, oocytes, morula, and early blastocysts, and observed differences between granulosa cells and various developmental stages of embryos in saturated FA, MUFA, and n-6 FA composition. The differences in distribution of FA classes between FF, granulosa cells, and COCs indicate on selective uptake of specific classes of FAs in ovarian compartments, as also suggested by Adamiak et al. (2006). Furthermore, as mentioned earlier in this study, there was an indication of selective uptake of specific n-3 FAs. The FA composition has an important role in maintaining the structure of the cell membrane, which influences the functionality of the cell (Fouladi-Nashta et al. 2009b), and this was also demonstrated in oocytes by Zeron et al. (2002). It may be 
concluded that the selective uptake of FA into the oocytes reflects the sensitivity of the oocytes to changes in membrane FA composition - which may lead to alterations in membrane viscosity that are associated with functional characteristics.

\section{Preovulatory follicle characteristics}

In this study, no differences between treatments were observed in preovulatory follicle characteristics, as was also found by Zachut et al. (2011). In another study, Ambrose et al. (2006) found that the diameter of ovulatory follicles was increased in cows fed flaxseed, which was not found in this study, by Mendoza et al. (2011) in grazing cows fed FO, or by Bilby et al. (2006) in lactating dairy cows. Furthermore, in this study, as in Zachut et al. (2011), no differences were observed between groups in steroid hormone concentrations. However, in another study, enhanced $\mathrm{P}_{4}$ concentrations were observed in ewes fed a mixture of flaxseed and FO (Wonnacott et al. 2010).

\section{Follicles and oocytes collected}

The number of small follicles appropriate for OPU was higher in both n-3 treatments than in the SFA treatment, which matches the findings of Zachut et al. (2010) in cows fed microencapsulated FLX and of Zeron et al. (2002) in ewes fed FO. A recent study by Mossa et al. (2012) demonstrated an association between follicle count during the first wave of follicular growth of the estrous cycle and reproductive performance in cattle, which was also found in humans by Baerwald et al. (2003). In other studies, Heravi Moussavi et al. (2007) found that cows that were fed FO increased the number of medium follicles (5-10 mm in diameter), but Petit et al. (2004) observed no effect of dietary flaxseed on follicle growth. There is inconsistency among findings on the effects of dietary PUFAs on folliculogenesis, and this may be attributable to differences between studies in the amounts of supplements, stage of lactation, and the metabolic status of the cows. In this study, the number of oocytes recovered was also higher in both $n-3$ groups than in the SFA group. Collectively, it can be concluded that dietary n-3 FAs increase folliculogenesis in ovaries, which may have positive effects on fertility performance, as was suggested by Evans et al. (2012) and Mossa et al. (2012).

In this study, the cleavage rate was higher in both n-3 treatments than in the SFA treatment, as was also found by Zachut et al. (2010) in cows fed microencapsulated FLX. However, Bilby et al. (2006) observed no differences in oocyte quality and cleavage rate between cows that were fed FLX at $140 \mathrm{~g} /$ day or linoleic acid (LA) at $71 \mathrm{~g} /$ day under heat stress conditions. The differences in the results between these studies may be attributed to season, i.e., summer vs winter; also, Zeron et al. (2001) showed that unsaturated FA contents in oocytes and granulosa cells were lower in summer than in winter. In another study, dairy cows were fed several unsaturated FAs and no effect on oocyte quality or cleavage rate was observed (Fouladi-Nashta et al. 2009b); however, in that study, the cows were fed for a short time of 25 days, and no alterations were found in the FA profile of granulosa cells, which may account for the unresponsiveness to FA supplementation. Omega-3 FAs may affect maturation and development of oocytes directly through alteration in membrane FA composition (Bender et al. 2010), or indirectly by influencing the concentrations of hormones and metabolites in the FF surrounding the oocytes (Fouladi-Nashta et al. 2009a).

Although the rate of development to blastocysts was relatively low in this study, it tended to be higher in cows fed either of the n-3 FA sources than in those fed SFA. This low rate of development to blastocysts from OPU was also found by Bilby et al. (2006), who suggested that oocytes collected from slaughterhouse ovaries underwent a postmortem effect during a few hours, through which the COCs became less tightly connected to the follicle wall and were, therefore, collected with a more complete morphology than OPU oocytes that were placed in maturation media within $20 \mathrm{~min}$, as in this study.

In conclusion, dietary ALA from FLX and EPA and DHA from $\mathrm{FO}$ were incorporated differently into plasma, milk, FF, granulosa cells, and COCs. In general, in the FLX cows, ALA was increased in all tissues, and in the FO cows, the proportions of EPA, DPAn-3, and DHA were enhanced. However, although considerable differences were observed between $n-3$ groups in FA composition in the ovarian compartments, no differences were observed in the beneficial effects of n-3 FAs on folliculogenesis, oocyte quality, and IVF performance. The present results of the study suggest that supplementing cows with FLX, which is the most widely available botanical source of $\mathrm{n}-3 \mathrm{FAs}$ and is preferable to $\mathrm{FO}$ in ruminant nutrition, represents a satisfactory approach to achieve improvement in folliculogenesis and oocyte fertilization.

\section{Declaration of interest}

The authors declare that there is no conflict of interest that could be perceived as prejudicing the impartiality of the research reported.

\section{Funding}

This research was financially supported by the Israeli Dairy Board, Yehud, Israel.

\section{Acknowledgements}

The authors would like to thank the entire staff of the experimental dairy farm at the Volcani Center (Bet Dagan, Israel) for their assistance with animal care. The authors also 
would like to thank Mr Maurizio Lorenzon and SILA company (Venice, Italy) for partly donating the fat supplements.

\section{References}

AbuGhazaleh AA, Schingoethe DJ, Hippen AR, Kalscheur KF \& Whitlock LA 2002 Fatty acid profiles of milk and rumen digesta from cows fed fish oil, extruded soybeans, or their blend. Journal of Dairy Science 85 2266-2276. (doi:10.3168/jds.S0022-0302 (02)74306-3)

Adamiak SJ, Powell K, Rooke JA, Webb R \& Sinclair KD 2006 Body composition, dietary carbohydrates and fatty acids determine postfertilisation development of bovine oocytes in vitro. Reproduction 131 247-258. (doi:10.1530/rep.1.00871)

Ambrose DJ, Kastelic JP, Corbett R, Pitney PA, Petit HV, Small JA \& Zalkovic P 2006 Lower pregnancy losses in lactating dairy cows fed a diet enriched in $\alpha$-linolenic acid. Journal of Dairy Science 89 3066-3074. (doi:10.3168/jds.S0022-0302(06)72581-4)

Baerwald AR, Adams GP \& Pierson RA 2003 Characterization of ovarian follicular wave dynamics in women. Biology of Reproduction 69 1023-1031. (doi:10.1095/biolreprod.103.017772)

Bender K, Walsh S, Evans ACO, Fair T \& Brennan L 2010 Metabolite concentrations in follicular fluid may explain differences in fertility between heifers and lactating cows. Reproduction 139 1047-1055. (doi:10.1530/REP-10-0068)

Bilby TR, Block J, do Amaral BC, Sa Filho O, Silvestre FT, Hansen PJ, Staples CR \& Thatcher WW 2006 Effects of dietary unsaturated fatty acids on oocyte quality and follicular development in lactating dairy cows in summer. Journal of Dairy Science 89 3891-3903. (doi:10.3168/ jds.S0022-0302(06)72432-8)

Cerri RLA, Juchem SO, Chebel RC, Rutigliano HM, Bruno RGS, Galvão KN, Thatcher WW \& Santos JEP 2009 Effect of fat sources differing in fatty acid profile on metabolic parameters, fertilization, and embryo quality in high-producing dairy cows. Journal of Dairy Science 92 1520-1531. (doi:10.3168/jds.2008-1614)

Childs S, Hennessy AA, Sreenan JM, Wathes DC, Cheng Z, Stanton C, Diskin MG \& Kenny DA 2008 Effect of level of dietary n-3 polyunsaturated fatty acid supplementation on systemic and tissue fatty acid concentrations and on selected reproductive variables in cattle. Theriogenology 70 595-611. (doi:10.1016/j.theriogenology. 2008.04.002)

Donovan DC, Schingoethe DJ, Baer RJ, Ryali J, Hippen AR \& Franklin ST 2000 Influence of dietary fish oil on conjugated linoleic acid and other fatty acids in milk fat from lactating dairy cows. Journal of Dairy Science 83 2620-2628. (doi:10.3168/jds.S0022-0302(00)75155-1)

Evans ACO, Mossa F, Walsh SW, Scheetz D, Jimenez-Krassel F, Ireland JLH, Smith GW \& Ireland JJ 2012 Effects of maternal environment during gestation on ovarian folliculogenesis and consequences for fertility in bovine offspring. Reproduction in Domestic Animals 47 (Suppl 4) 31-37. (doi:10.1111/j.1439-0531.2012.02052.x)

Fouladi-Nashta AA, Marei W \& Wathes DC 2009a Diverse effects of polyunsaturated fatty acids on oocyte maturation and development in vitro. Reproduction in Domestic Animals 44 (Suppl 1) 71.

Fouladi-Nashta AA, Wonnacott KE, Gutierrez CG, Gong JG, Sinclair KD, Garnsworthy PC \& Webb R 2009b Oocyte quality in lactating dairy cows fed on high levels of $n-3$ and n-6 fatty acids. Reproduction 138 771-781. (doi:10.1530/REP-08-0391)

Gonthier C, Mustafa AF, Ouellet DR, Chouinard PY, Berthiaume R \& Petit HV 2005 Feeding micronized and extruded flaxseed to dairy cows: effects on blood parameters and milk fatty acid composition. Journal of Dairy Science 88 748-756. (doi:10.3168/jds.S0022-0302 (05)72738-7)

Heravi Moussavi AR, Gilbert RO, Overton TR, Bauman DE \& Butler WR 2007 Effects of feeding fish meal and n-3 fatty acids on ovarian and uterine responses in early lactating dairy cows. Journal of Dairy Science 90 145-154. (doi:10.3168/jds.S0022-0302(07)72616-4)

Ireland JJ \& Roche F 1982 Development of antral follicles in cattle after prostaglandin-induced luteolysis: changes in serum hormones, steroids in follicles fluids and gonadotropin receptors. Endocrinology 111 2077-2086. (doi:10.1210/endo-111-6-2077)
Leroy J, Vanholder T, Mateusen B, Christophe A, Opsomer G, de Kruif A, Genicont G \& van Soom A 2005 Non-esterified fatty acids in follicular fluid of dairy cows and their effect on developmental capacity of bovine oocytes in vitro. Reproduction 130 485-495. (doi:10.1530/ rep.1.00735)

de Loos F, van Vliet C, van Maurik P \& Kruip TA 1989 Morphology of immature bovine oocytes. Gamete Research 24 197-204. (doi:10.1002/ mrd.1120240207)

Mattos R, Staples CR \& Thatcher WW 2000 Effects of dietary fatty acids on reproduction in ruminants. Reviews in Reproduction $\mathbf{5}$ 38-45. (doi:10.1530/ror.0.0050038)

Mendoza A, Crespi D, Hernandez A, Roura N, Valentin H \& La Manna A 2011 Effect of dietary supplementation with fish oil during the transition period on milk production, plasma metabolites and postpartum anoestrus interval in grazing dairy cows. Animal Production Science 51 481-489. (doi:10.1071/AN10178)

Moallem U \& Zachut M 2012 Short communication: the effects of supplementation of various n-3 fatty acids to late-pregnant dairy cows on plasma fatty acid composition of the newborn calves. Journal of Dairy Science 95 4055-4058. (doi:10.3168/jds.2012-5457)

Moallem U, Folman Y, Bor A, Arav A \& Sklan D 1999 Effect of calcium soaps of fatty acids and administration of somatotropin on milk production, preovulatory follicular development, and plasma and follicular fluid lipid composition in high yielding dairy cows. Journal of Dairy Science 82 2358-2368. (doi:10.3168/jds.S00220302(99)75486-X)

Moallem U, Katz M, Lehrer H, Livshitz L \& Yakoby S 2007 Role of peripartum dietary propylene glycol or protected fats on metabolism and early postpartum ovarian follicles. Journal of Dairy Science $\mathbf{9 0}$ 1243-1254. (doi:10.3168/jds.S0022-0302(07)71613-2)

Mossa F, Walsh SW, Butler ST, Berry DP, Carter F, Lonergan P, Smith GW, Ireland JJ \& Evans ACO 2012 Low numbers of ovarian follicles $\geq 3 \mathrm{~mm}$ in diameter are associated with low fertility in dairy cows. Journal of Dairy Science 95 2355-2361. (doi:10.3168/jds.2011-4325)

Parrish JJ, Susko-Parrish JL, Critser ES, Eyestone WH \& First NL 1986 Bovine in vitro fertilization with frozen-thawed semen. Theriogenology 25 591-600. (doi:10.1016/0093-691X(86)90143-3)

Petit HV, Germiquet C \& Lebel D 2004 Effect of feeding whole, unprocessed sunflower seeds and flaxseed on milk production, milk composition, and prostaglandin secretion in dairy cows. Journal of Dairy Science $\mathbf{8 7} \quad 3889-3898 . \quad$ (doi:10.3168/jds.S0022-0302 (04)73528-6)

Ponter AA, Parsy AE, Saade M, Mialot JP, Ficheux C, Duvaux-Ponter C \& Grimard B 2006 Effect of a supplement rich in linolenic acid added to the diet of postpartum dairy cows on ovarian follicle growth, and plasma fatty acid compositions. Reproduction and Nutrition Development $\mathbf{4 6}$ 19-29. (doi:10.1051/rnd:2005058)

Reis A, Mitchell LM, Rooke JA, Ewen M, Lomax MA, Robinson JJ \& McEvoy TG 2002 Fatty acid profiles during development of sheep eggs in vivo. Theriogenology 57507 (Abstr).

Robinson RS, Pushpakumara PG, Cheng Z, Peters AR, Abayasekara DR \& Wathes DC 2002 Effects of dietary polyunsaturated fatty acids on ovarian and uterine function in lactating dairy cows. Reproduction 124 119-131. (doi:10.1530/rep.0.1240119)

SAS 2002 User's Guide: Statistics, Version 9.2 Edition. SAS Inst., Cary, NC. Simopoulos AP 2002 Omega-3 fatty acids in inflammation and autoimmune diseases. Journal of the American College of Nutrition 21 495-505. (doi:10.1080/07315724.2002.10719248)

Staples CR, Burke JM \& Thatcher WW 1998 Influence of supplemental fats on reproductive tissues and performance of lactating cows. Journal of Dairy Science $\mathbf{8 1}$ 856-871. (doi:10.3168/jds.S00220302(98)75644-9)

Wang Y, Botolin D, Christian B, Busik J, Xu J \& Jump DB 2005 Tissuespecific, nutritional, and developmental regulation of rat fatty acid elongases. Journal of Lipid Research 46 706-715. (doi:10.1194/jlr. M400335-JLR200)

Wathes DC, Abayasekara DRE \& Aitken RJ 2007 Polyunsaturated fatty acids in male and female reproduction. Biology of Reproduction 77 190-201. (doi:10.1095/biolreprod.107.060558)

Whitlock LA, Schingoethe DJ, Hippen AR, Kalscheur KF, Baer RJ, Ramaswamy N \& Kasperson KM 2002 Fish oil and extruded soybeans 
fed in combination increase conjugated linoleic acids in milk of dairy cows more than when fed separately. Journal of Dairy Science $\mathbf{8 5}$ 234-243. (doi:10.3168/jds.S0022-0302(02)74072-1)

Wonnacott KE, Kwong WY, Hughes J, Salter AM, Lea RG, Garnsworthy PC \& Sinclair KD 2010 Dietary omega-3 and -6 polyunsaturated fatty acids affect the composition and development of sheep granulosa cells, oocytes and embryos. Reproduction 139 57-69. (doi:10.1530/REP-09-0219)

Zachut M, Dekel I, Lehrer H, Arieli A, Arav A, Livshitz L, Yakoby S \& Moallem U 2010 Effects of dietary fats differing in n-6:n-3 ratio fed to high-yielding dairy cows on fatty acid composition of ovarian compartments, follicular status, and oocyte quality. Journal of Dairy Science 93 529-545. (doi:10.3168/jds.2009-2167)

Zachut M, Arieli A \& Moallem U 2011 Incorporation of dietary n-3 fatty acids into ovarian compartments in dairy cows and the effects on hormonal and behavioral patterns around estrus. Reproduction 141 833-840. (doi:10.1530/REP-10-0518)
Zeron Y, Ocheretny A, Kedar O, Borochov A, Sklan D \& Arav A 2001 Seasonal changes in bovine fertility: relation to developmental competence of oocytes, membrane properties and fatty acid composition of follicles. Reproduction 21 447-454. (doi:10.1530/ rep.0.1210447)

Zeron Y, Sklan D \& Arav A 2002 Effect of polyunsaturated fatty acid supplementation on biophysical parameters and chilling sensitivity of ewe oocytes. Molecular Reproduction and Development 61 271-278. (doi:10.1002/mrd.1156)

Received 5 June 2013

First decision 12 August 2013

Revised manuscript received 20 August 2013

Accepted 23 September 2013 